\title{
Pre-Existing Cytokine and NLRP3 Inflammasome Activation and Increased Vascular Permeability in Diabetes: A Possible Fatal Link With Worst COVID-19 Infection Outcomes?
}

\begin{abstract}
Vaia Lambadiari ${ }^{1 *}$, Foteini Kousathana ${ }^{1}$, Athanasios Raptis ${ }^{1}$, Konstantinos Katogiannis ${ }^{2}$, Alexander Kokkinos ${ }^{3}$ and Ignatios Ikonomidis ${ }^{2}$

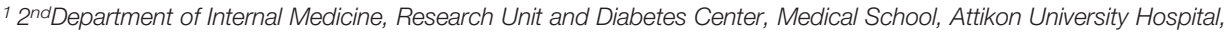
National and Kapodistrian University of Athens, Athens, Greece, $22^{\text {nd }}$ Cardiology Department, Attikon University Hospital, Medical School, National and Kapodistrian University of Athens, Athens, Greece, ${ }^{3} 1^{\text {st }}$ Department of Propaedeutic Internal Medicine, Medical School, Diabetes Center, Laiko Hospital, National and Kapodistrian University of Athens, Athens, Greece
\end{abstract}

Keywords: cytokine, diabetes, glycocalyx, inflammasome, inflammation

\section{INTRODUCTION}

SARS-CoV-2, a novel RNA contaminating coronavirus emerged in Wuhan, China at the end of 2019 (COVID-19). In March 11, 2020 the World Health Organization declared it a pandemic disease. Since April 14, 2010 the pandemia has been spread to 3,170,474 people and led to 220,324 deaths (1). Findings from a February report from the Chinese Center for Disease Control and Prevention have shown that of 44,672 cases the overall case-fatality rate (CFR) was $2.3 \%$. CFR was elevated among COVID-19 patients with comorbidities, such as cardiovascular disease (10.5\%) and diabetes (7.3\%) (2).

Patients with uncontrolled diabetes may be at extra risk of COVID-19 mortality or complications of the disease. The pathophysiology remains unknown, although it is of great interest because of the great prevalence of diabetes; In 2019, 463 million of adults 20-79 years old were living with diabetes, and by 2045 this number is suggested to rise to 700 million (3).

\section{COVID-19: POSSIBLE MECHANISMS OF INCREASED RISK COMPLICATIONS IN DIABETIC PATIENTS}

Published: 23 November 2020

Citation:

Lambadiari V, Kousathana F, Raptis A, Katogiannis K, Kokkinos A and Ikonomidis I (2020) Pre-Existing Cytokine and NLRP3 Inflammasome Activation and Increased Vascular

Permeability in Diabetes: A Possible

Fatal Link With Worst COVID-19

Infection Outcomes?

Front. Immunol. 11:557235.

doi: 10.3389/fimmu.2020.557235

\section{The Role of NLRP3 Inflammasome in COVID-19 and Its Complications}

In COVID-19 the immune system may react with an exacerbation of cytokine production known as a "cytokine storm" which leads to hyperinflammation and secondary hemophagocytic lymphohistiocytosis (sHLH) or else Macrophage Activation Syndrome (MAS). This is

Abbreviations: ACE-2, angiotensin-converting enzyme-2; ALI, acute lung injury; ARDS, acute respiratory distress syndrome; IL, interleukin; INF, interferon; MAS, macrophage activation syndrome; NK, natural killer; NLRP3, nucleotide-binding domain, leucine-rich-containing family, pyrin domain-containing-3; sHLH, secondary hemophagocytic lymphohistiocytosis; TNF, tumor necrosis factor. 
characterized by fulminant, fatal hypercytokinemia, multiple organ failure, Acute Respiratory Distress Syndrome (ARDS), and sepsis (4). NLRP3 inflammasome seems to play an important role in these complications (5).

Particularly, numerous studies have implicated the NLRP3 inflammasome and IL-1 $\beta$ in mediating inflammation during lung injury and ARDS $(6,7)$. In ARDS/ALI, IL-1 $\beta$ is one of the most biologically active proinflammatory cytokines in the lungs, while inflammasome hyperactivation participates in both ARDS and mechanical ventilation acute lung injury. IL-1 $\beta$ levels are shown to be elevated in plasma and bronchoalveolar fluid of patients with ARDS (8). In patients with ARDS infected with MERS-CoV and SARS-CoV, IL-1 $\beta$, IL-6, and IL-8 levels were also found high $(9,10)$ In other respiratory viral infections such as influenza, IL-1 $\beta$ levels were also elevated in patients with lung injury, whereas the use of antagonists of IL- $1 \beta$ reduced it, which indicates an important role of IL-1 $\beta$ in the pathogenesis of complications in viral infections such as SARS-CoV infections $(11,12)$.

The SARS-CoV genome encodes three ion channels proteins: $\mathrm{E}$, open reading frame $3 \mathrm{a}$ (ORF3a), and ORF8a. E and ORF3a proteins are required for the replication of the virus (13). SARSCoV-2 enters the alveolar epithelial cells leading to their injury and apoptosis. Then the apoptotic pneumocytes release dangerand pathogen-associated molecular patterns which trigger inflammasomes of alveolar macrophages. NLRP3 inflammasome is also triggered by SARS-CoV-2 through other pathways: a) through the proteins $\mathrm{E}, 3 \mathrm{a}$, and $8 \mathrm{~b}$ of SARS-CoV, b) after the binding of the spike protein of the virus to ACE2 receptors of pneumonocytes, c) after the activation of the renin-angiotensinaldosterone system (RAAS) leading to elevated levels of angiotensin II, which following the binding to angiotensin I receptor activates inflammasome, d) through the activation of the complement cascade by the $\mathrm{N}$ proteins of the SARS-CoV-2, which results in the release of complement fragments (C3a and C5a anaphylatoxins) which may upregulate inflammasome in cells (14). NLRP3 inflammasome activation leads to a release of IL-1 $\beta$, IL-18, and TNF- $\alpha$, initiating a cascade of secretion of proinflammatory cytokines, cell apoptosis, and tissue injury (15). IL- $1 \beta$ leads to overproduction of INF- $1 \gamma$ by NK cells leading to hemophagocytosis. Cytokine storm may cause dysfunction of $\mathrm{NK}$ and $\mathrm{CD}$ cells and may include other proinflammatory cytokines or chemokines such as IL-17, IL-21, IL-22, IL-6, TNF- $\alpha$, chemokine ligand 10 and 2, IL-2R, IL-8, IL-10, which may also participate in ARDS/ALI and multi-organ failure (4). NLRP3 activation promotes pyroptosis, a programmed cell death of immune cells which increases intracellular pathogen clearance. After pyroptosis, IL-1 $\beta$ and IL-18 are secreted again stimulating inflammasome. Thus, pyroptosis has a double role for innate immunity. It protects from infections, and on the other hand, it may lead to chronic inflammation, too (16).

In sHLH/MAS, immunomodulation may be beneficial. Tocilizumab (IL-6 receptor blockage, licensed for cytokine release syndrome) has already been approved for COVID-19 pneumonia in China (17), while Anakinra (IL-1 $\beta$ blockage) has shown surveillance benefit in patients with hyperinflammation (18).

\section{Pre-Existing Overactivation of NLRP3 Inflammasome in Diabetes and Its Role in COVID-19 Complications}

Diabetes is shown to be among the most frequently reported comorbidities in patients with COVID-19 (1, 2, 19, 20). However, the prevalence of diabetes among these patients is shown to be $8-10 \%$, as in the general population, which would suggest that diabetes is not a risk factor for contracting COVID$19(21,22)$, but it is associated with increased mortality and severity of disease in COVID-19 pneumonia (23). This implies that diabetic patients are at higher risk of a cytokine storm, metabolic and immune derangement.

Chronic hyperglycemia deranges immune function and increases the risk for bad outcomes due to various infections such as pneumococcal pneumonia, SARS, MERS, and H1N1 (24). Obesity and type 2 diabetes have also been considered an independent risk factor for sepsis and high mortality (25) and can lead to severe pneumonia, hepatic injury, hypercoagulation and hyperinflammation during COVID-19 infection $(26,27)$. A possible mechanism may be that in T2DM NLRP3 inflammasome action is upregulated leading diabetes to be a state of low-grade inflammation. Hyperglycemia is also strongly associated with an increased mortality in COVID-19 pneumonia even in patients without diabetes (28).

Glyco-lipotoxicity and oxidative stress increase products of the intermediate metabolism such as urate, cholesterol crystals, extracellular ATP, certain fatty acids (e.g. ceramides) and islet amyloid peptides, resulting to hyperactivation of inflammasome and caspase- 1 which in turn, increases the release of IL-1 $\beta$ and IL-18 (29). NLRP3 inflammasome hyperactivation in diabetes, pyroptosis, and low-grade inflammation lead to a delay of INF- $\gamma$ response and lower CD4+ and CD8+ cell numbers (30, 31). CD4+ and CD8+ decrease is associated with poor prognosis, whereas recovery of lymphocyte count coincides with clinical improvement $(32,33)$. Indeed, according to mouse model experiments, in the absence of $\mathrm{CD} 4+$ there was much more severe interstitial pneumonitis, whereas the depletion of both CD4+ and CD8+ led to an increase of neutrophils and macrophages in the lesions (34). The delay of INF- $\gamma$ response and inflammatory monocytes and macrophage accumulation are the main causes of lethal pneumonia as it has been proved in a mouse model of SARSCoV infection (35).

In addition, this state of low-grade inflammation in COVID-19 diabetic patients may lead to an increase of the percentage of proinflammatory memory $B$ cells and a decrease of antiinflammatory B-cells, resulting in an early maturation of the antibody response. In that way, Secchi $\mathrm{M}$ et al. have indicated that SARS-CoV-2 antigens, such as the SARS-CoV-2 spike Receptor Binding Domain, lead to a rapid development of humoral response and superimposable antibody response compared to non-diabetic patients independently of glucose levels $(28,36)$.

Chronic NLRP3 inflammasome overactivity leads also to lung injury and fibrosis, cardiomyopathy, and other damage $(37,38)$ which may make diabetic patients vulnerable to bad outcomes after an infection. Weinand B. et al. found that alveolar epithelial and endothelial capillary basal laminae were significantly thicker 
in samples from diabetic patients. This insult to the integrity of alveolo-capillary membrane of the lung affects the alveolar gas exchange and pulmonary function in diabetic patients (39).

Endothelial to mesenchymal transition (EndMT) may contribute to interstitial organ fibrosis, including pulmonary fibrosis in COVID-19 (40). Endothelial cells undergoing EndMT change their morphology and increase their mesenchymal proteins. This results in the breakdown of the underlying basement membrane and cell migration (41). Mechanical ventilation resulting in NLRP3 inflammasome activation facilitates EndMT. Indeed, in vitro studies have shown that pulmonary fibrosis and EndMT were ameliorated in NLRP3-deficient mice (42).

Furthermore, downstream activation of toll-like receptor signal regulators such as IRAK4 (interleukin-1 receptor associated kinase 4) leading to TRAF6 (tumor necrosis factor receptor-associated factor 6 )-nuclear factor- $\kappa \mathrm{B}$ activation can alter monocyte migration and accelerate myocarditis, too (43).

Since it is suggested that the main role of NLRP3 inflammasome in the pathogenesis of SARS-CoV-2 complications is its overactivation contributing to cytokine storm and pyroptosis (14); overactivation of inflammasome in diabetes too may also suggest a reason for the susceptibility of diabetic patients to complications and lung injury with COVID-19 infection. A common therapeutic approach to SARS-CoV-2 complications (5) and type 2 diabetes with IL-1 blockade agents (44) can strengthen the suggestion of the association of type 2 diabetes and COVID-19 complications.

\section{Increased Vascular Permeability and Its Role in COVID-19 Complications}

Increased vascular permeability in diabetes may also contribute to the susceptibility of COVID-19 diabetic patients in ARDS and sepsis. Micro-angiopathic changes may be present in the respiratory tract of diabetic patients, interfering with gas exchanges and lung compliance (45). Endothelial glycocalyx is a major determinant of vascular permeability during inflammatory stress. Diabetic patients have impaired glycocalyx thickness due to oxidative stress which is partially restored after optimal glycemic control (46). Increased vascular permeability may promote extravascular or interstitial exudates in COVID-19 infection as has been shown in sepsis (47). In a septic state, inflammatory macrophages may release cytokines, such as IL-1 $\beta$ and IL- 6 that induce the expression of adhesion molecules, inflammatory cell infiltration, and vascular inflammation. Endothelial cells, also, release proinflammatory cytokines which contribute to the creation and proliferation of microcirculatory lesions (48). So, the dysfunctional endothelium becomes proadhesive and procoagulant (48).

Interleukin-6, a hallmark cytokine in COVID-19 infection, promotes endothelial dysfunction (49) and also local enhancement of thrombosis (50). Recently, increased IL-6 production leading to lymphopenia and its reversal by tocilizumab, an IL-6 inhibitor, has been described in critically ill COVID-19 patients in need of mechanical ventilation (51). Indeed, tocilizumab improves endothelial function leading to an increase of effective myocardial work through a profound reduction of inflammatory burden and oxidative stress, which may explain its positive effects on COVID-19 and its complications (52). Both IL- $1 \beta$ and IL-6 exert detrimental effects on vascular, coronary, and myocardial function during uncontrolled inflammation such as exacerbation of rheumatoid arthritis and their inhibition by biological agents to reverse these adverse effects $(53,54)$.
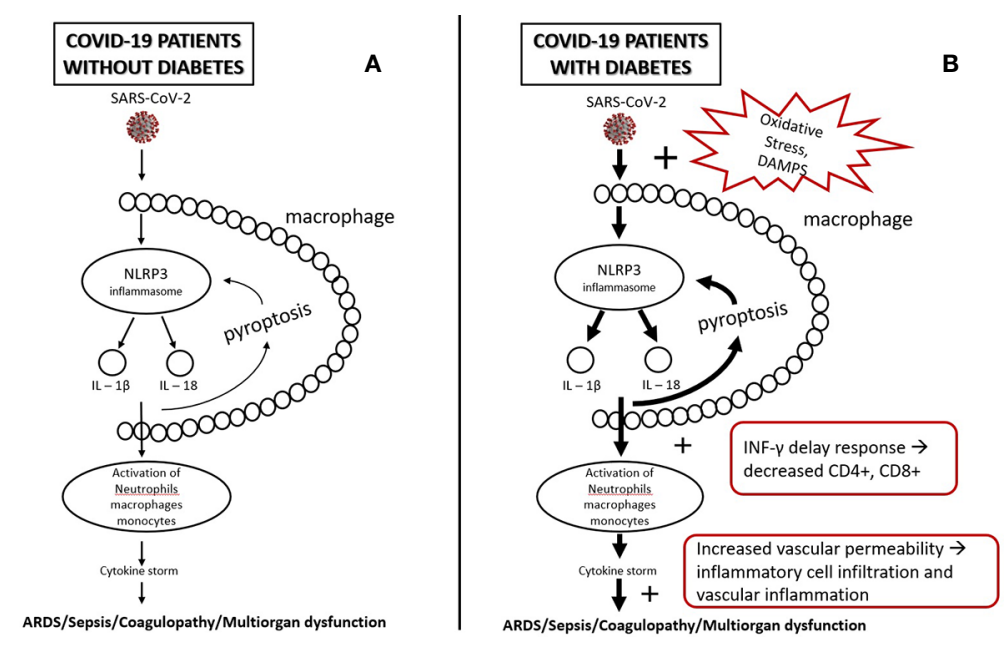

FIGURE 1 | (A) SARS-CoV-2, after infection, triggers NLRP3 inflammasomes of alveolar macrophages. NLRP3 activation leads to a release of IL-1 $\beta$, IL-18, and pyroptosis which, in turn, triggers inflammasome and leads to activation of other immune cells (e.g., neutrophils, lymphocytes, monocytes). This may initiate a cascade of secretion of proinflammatory cytokines (cytokine storm), leading to tissue injury and multiorgan failure. (B) In diabetes, oxidative stress and DAMPS (Damage-Associated Mollecular Patterns) overactivate inflammasomes leading to a state of low-grade inflammation and a more intense secretion of proinflammatory cytokines. Low-grade inflammation leads to a delay of INF- $\gamma$ response, lymphopenia, and greater accumulation of inflammatory macrophages and monocytes, which, in combination with the increased vascular permeability and damaged glycocalyx, may increase the risk for tissue injury and multiorgan failure. 
These mechanisms may lead to susceptibility of endothelial glycocalyx during COVID-19 infection resulting in increased vascular permeability and rapid deterioration to lung alveolar exudation and pneumonitis needing mechanical ventilation (51). Glycemic oscillations in diabetes have also been suggested to increase endothelial cytokine and adhesion molecule production which, in turn, may lead to an uncontrolled extravasation of leukocytes in the alveolus during influenza infection, promoting lung damage and impairment in respiratory function $(55,56)$. Increased vascular lesions and endothelial inflammation put individuals with diabetes at greater risk for endothelitis in several organs whereas change of vascular change and vasoconstriction can lead to organ ischemia, tissue edema, and a procoagulant state (57). Thus, endothelial glycocalyx impairment by IL-1 $\beta$, IL-6, and oxidative stress in diabetic patients may be a mechanism explaining their susceptibility to worse COVID-19 infection prognosis.

\section{DISCUSSION}

Diabetes is characterized by abnormally elevated glucose levels and oxidative stress. Poorly uncontrolled diabetes increases the risk of infections, hospitalizations, and mortality $(58,59)$. Numerous clinical studies during the 2019 influenza pandemic showed an increased susceptibility of individuals with diabetes for bad outcomes (60-62). Many recent studies have also suggested that in the new pandemic COVID-19 diabetes is one of the leading comorbidities associated with infection severity (1, $2,19,20)$. The mechanisms through which diabetes is associated with COVID-19 severity are proposed to be: the increased ACE2 receptor expressed in diabetic tissues, the dysregulation of diabetic immune system, the alveolar dysfunction, the endothelial dysfunction, and coagulopathy because of low grade inflammation and oxidative stress (31).

\section{REFERENCES}

1. Guan W, Ni Z, Hu Y, Liang WH, Ou CQ, He JX, et al. Clinical Characteristics of Coronavirus Disease 2019 in China. N Engl J Med (2020) 382(18):1708-20. doi: 10.1056/NEJMoa2002032

2. Wu Z, McGoogan JM. Characteristics of and Important Lessons From the Coronavirus Disease 2019 (COVID-19) Outbreak in China: Summary of a Report of 72314 Cases From the Chinese Center for Disease Control and Prevention. JAMA (2020) 323(13):1239-42. doi: 10.1001/jama.2020.2648

3. Saeedi P, Petersohn I, Salpea P, Malanda B, Karuranga S, Unwin N, et al. Global and regional diabetes prevalence estimates for 2019 and projections of 2030 and 2045: Results from the International Diabetes Federation Diabetes Atlas, 9(th) edition. Diabetes Res Clin Pract (2019) 157:107843. doi: 10.1016/ j.diabres.2019.107843

4. McGonagle D, Sharif K, O'Regan A, Bridgewood C. The Role of Cytokines including Interleukin-6 in COVID-19 induced Pneumonia and Macrophage Activation Syndrome-Like Disease. Autoimmun Rev (2020) 19(6):102537. doi: 10.1016/j.autrev.2020.102537

5. Freeman TL, Swartz T. Targeting the NLRP3 inflammasome in severe COVID-19. Front Immunol (2020) 11:1518. doi: 10.3389/fimmu.2020.01518

6. Olman MA, White KE, Ware LB, Simmons WL, Benveniste EN, Zhu S, et al. Pulmonary edema fluid from patients with early lung injury stimulates fibroblast proliferation through IL-1 beta -induced IL-6 expression. J Immunol (2004) 172:2668-77. doi: 10.4049/jimmunol.172.4.2668
SARS-CoV-2 invasion activates inflammasome of the alveolar macrophages leading to further activation of the immune response which may result in a cascade of proinflammatory cytokine secretion, ARDS, and sepsis $(5,30,31)$.

In diabetes glyco-lipotoxicity and oxidative stress increase the products of intermediate metabolism and danger-associated molecular patterns (DAMPS) which hyperactivate NLRP3 inflammasome of the macrophages which, in turn hyperactivate further the innate and acquired immunity, leading to a dysregulated immune response, a delay in INF- $\gamma$ response, a prolonged hyperinflammatory state, and lower CD4+ and CD8+ numbers $(31,63)$. Furthermore, damaged glycocalyx and increased vascular permeability may promote extravascular or interstitial exudates in sepsis in COVID-19 $(47,48)$. Increased vascular lesions in diabetic individuals lead to greater risk of endothelitis in several organs, organ ischemia, tissue edema, and multi-organ dysfunction $(32,57)$ (Figure 1).

So, we hypothesize that the pre-existing hyperactivation of NLRP3 inflammasome, hypercytokinemia, chronic inflammation and increased vascular permeability in uncontrolled diabetes could be major contributing factors for the development of severe COVID-19 complications. Such patients could be good candidates for therapeutic intervention with colchicine, anti-IL1a, anti-IL1 $\beta$, or anti-IL6 biological agents early in the course of COVID-19 infection to prevent cytokine storm, lung, and cardiovascular complications. Of course this remains to be investigated through randomized controlled studies.

\section{AUTHOR CONTRIBUTIONS}

All authors contributed to the article and approved the submitted version.

7. Kolb M, Margetts PJ, Anthony DC, Pitossi F, Gauldie J. Transient expression of IL-1 beta induces acute lung injury and chronic repair leading to pulmonary fibrosis. J Clin Invest (2001) 107:1529-36. doi: 10.1172/JCI12568

8. Bouros D, Alexandrakis MG, Antoniou KM, Agouridakis P, Pneumatikos I, Anevlavis S, et al. The clinical significance of serum and bronchoalveolar lavage inflammatory cytokines in patients at risk for acute respiratory distress syndrome. Am J Respir Crit Care Med (2001) 164:1896-903. doi: 10.1164/ ajrccm.164.10.21040139

9. He L, Ding Y, Zhang Q, Che X, He Y, Shen H, et al. Expression of elevated levels of proinflammatory cytokines in SARS-CoV infected ACE+ cells in SARS patients: relation to the acute lung injury and pathogenesis of SARS. J Pathol (2006) 210:288-97. doi: 10.1002/path.2067

10. Min CK, Cheon S, Ha NY, Sohn KM, Kim Y, Aigerim A, et al. Comparative and kinetic analysis of viral shedding and immunological responses in MERS patients representing a broad spectrum of disease severity. Sci Rep (2016) 6:25359. doi: 10.1038/srep25359

11. Gasse P, Mary C, Guenon I, Noulin N, Charron S, Schnynder-Candrian S, et al. IL-1R1/MyD88 signaling and the inflammasome are essential in pulmonary inflammation and fibrosis in mice. J Clin Invest (2007) 117:3786-99. doi: 10.1172/JCI132285

12. Kim KS, Jung H, Shin IK, Choi BR, Kim DH. Induction of interleukin 1 beta (IL$1 \beta)$ is a critical component of lung inflammation during influenza A (H1N1) virus infection. J Med Virol (2015) 87:1104-12. doi: 10.1002/jmv.24138 
13. Castano-Rodriguez C, Honrubia JM, Gutierrege-Alvarez J, DeDiego ML, Nieto-Torres JL, Jimenez-Guardeno JM, et al. Role of severe acute respiratory syndrome coronavirus viroporins $\mathrm{E}, 3 \mathrm{a}$ and $8 \mathrm{a}$ in replication and pathogenesis. mBio (2018) 9:e02325-17. doi: 10.1128/mBio.02325-17

14. Ratajczak MZ, Kucia M. SARS-CoV-2 infection and overactivation of Nlrp3 inflammasome as a trigger of cytokine "storm" and risk factor for damage of hematopoietic stem cells. Leukemia (2020) 34(7):1726-9. doi: 10.1038/s41375-0200887-9

15. Fu Y, Cheng Y, Wu Y. Understanding SARS-CoV2-mediated inflammatory responses: from mechanisms to potential therapeutic tools. Virol Sin (2020) 35 (3):266-71. doi: 10.1007/s12250-020-00207-4

16. Shi J, Zhao Y, Wang K, Shi X, Wang Y, Huang H, et al. Cleavage of GSDMD by inflammatory caspases determines pyroptotic cell death. Nature (2015) 526:660-5. doi: 10.1038/nature15514

17. Chinese Clinical Trial Registry. A multicenter, randomized controlled trial for the efficacy and safety of tocilizumab in the treatment of new coronavirus pneumonia (COVID-19). Available at: http://www.chictr.org.cn/showprojen. aspx?proj=49409 (Accessed 6 March 2020).

18. Shakoory B, Carcillo JA, Chathamn WW, Amdur RL, Zhao H, Dinarello CA, et al. Opal SM Interleukin-1 receptor blockade is associated associated with reduced mortality in sepsis patients with features of macrophage activation syndrome: reanalysis of a prior phase iii trial. Crit Care Med (2016) 44:275-81. doi: 10.1097/CCM.0000000000001402

19. Goyal P, Choi J, Pinheiro L, Schenck E, Chen R, Jabri A. Clinical characteristics of COVID-19 in New York City. N Engl J Med (2020) 382(24):2372-4. doi: 10.1056/ NEJMc2010419

20. Wang D, Hu B, Zhu F, Liu X, Zhang J, Wang B. Clinical characteristics of 138 hospitalised patients with 2019 novel Coronavirus-infected pneumonia in Wuhan, China. JAMA (2020) 323(11):1061-9. doi: 10.1001/jama..1585

21. Fadini GP, Morieri ML, Longato E, Avogaro A. Prevalence and impact of diabetes among people infected with SARS-CoV-2. J Endocrinol Invest (2020) 43(6):867-9. doi: 10.1007/s40618-020-01236-2

22. World Health Organisation. Available at: https://www.who.int/diabetes/ country-profiles (Accessed 14 April 2020).

23. Huang I, Lim MA, Pranata R. Diabetes mellitus is associated with increased mortality and severity of disease in COVID-19 pneumonia - a systematic review, meta-analysis, and meta-regression. Diabetes Metab Syndr (2020) 14:395-403. doi: 10.1016/j.dsx.2020.04.018

24. Hussain A, Bhowmik B, do Vale Moreira NC. COVID-19 and diabetes: knowledge in progress. Diabetes Res Clin Pract (2020) 162:108142. doi: 10.1016/ j.diabres.2020.108142

25. Frydrych LM, Bian G, O'Lone DE, Ward PA, Delano MJ. Obesity and type 2 diabetes mellitus drive immune dysfunction, infection development, and sepsis mortality. J Leukoc Biol (2018) 104(3):525-34. doi: 10.1002/ JLB.5VMR0118-021RR

26. Merad M, Matin JC. Pathological inflammation in patiens with COVID-19: a key role for monocytes and macrophages. Nat Rev Immunol (2020) 20:35562. doi: 10.1038/s41577-020-0331-4

27. Korakas E, Ikonomidis I, Kousathana F, Balampanis K, Kountouri A, Raptis A, et al. Obesity and COVID-19: immune and metabolic derangement as a possible link to adverse clinical outcomes (2020). Am J Physiol Endocrinol Metab (2020) 319(1):E105-9. doi: 10.1152/ajpendo.00198

28. Lampasona V, Secchi M, Scavini M, Bazzigaluppi E, Brigatti C, Marzinotto L, et al. Antibody response to multiple antigens of SARS-CoV-2 in patients with diabetes: an observational cohort study. Diabetologia (2020) 63(12):2548-58. doi: 10.1007/s00125-020-05284-4

29. Zhou R, Tardivel A, Thorens B, Choi I, Tschopp J. Thierodoxin-interacting protein links oxidative stress to inflammasome activation. Nat Immunol (2010) 11(2):136-40. doi: 10.1038/ni.1831

30. Tay MZ, Poh CM, Renia L, MacAry PA, Ng LFP. The trinity of COVID-19: immunity, inflammation and intervention. Nat Rev Immunol (2020) 20 (6):363-74. doi: 10.1038/s41577-020-0311-8

31. Erener S. Diabetes, infection risk and COVID-19. Mol Metab (2020) 39:101044. doi: 10.1016/j.molmet.2020.101044

32. He Z, Zhao C, Dong Q, Zhuang H, Song S, Peng G, et al. Effects of severe acute respiratory syndrome (SARS) coronavirus infection on peripheral blood lymphocytes and their subsets. Int J Infect Dis (2005) 9:323-30. doi: 10.1016/ j.ijid.2004.07.014
33. Wong RS, Wu A, To KF, Lee N, Lam CW, Wong CK, et al. Haematological manifestations in patients with severe acute respiratory syndrome: retrospective analysis. BMJ; (2003) 326:1358-62. doi: 10.1136/bmj.326.7403.1358

34. Chen J, Lau YF, Lamirande EW, Paddock CD, Bartlett JH, Zaki SR, et al. Cellular immune responses to severe acute respiratory syndrome coronavirus (SARS-CoV) infection in senescent BALB/c mice: $\mathrm{CD} 4+\mathrm{T}$ cells are important in control of SARS-CoV infection. J Virol (2010) 84:1289-301. doi: 10.1128/ JVI.01281-09

35. Channappanavar R, Fehr AR, Vijay R, Mack M, Zhao J, Meyerholz DK. Dysregulated type I interferon and inflammatory monocyte-macrophage responses cause lethal pneumonia in SARS-CoV-infected mice. Cell Host Microbe (2016) 19(2):181-93. doi: 10.1016/j.chom.2016.01.007

36. Secchi M, Bazzigaluppi E, Brigatti C, Marzinotto I, Tresoldi C, Rovere-Querini $\mathrm{P}$, et al. COVID-19 survival associates with the immunoglobulin response to the SARS-CoV-2 spike Receptor Binding Domain. JClin Invest (2020) 142804. doi: 10.1172/JCI142804

37. Pinkerton J, Kim R, Robertson A, Hirota J, Wood L, Knight D. Inflammasomes in the lung. Mol Immunol (2017) 86:44-55. doi: 10.1016/j.molimm.2017.01.014

38. Sharma A, Tate M, Mathew G, Vince JE, Ritchie RH, de Haan JB. Oxidative Stress and NLRP3-Inflammasome Activity as Significant Drivers of Diabetic Cardiovascular Complications: Therapeutic Implications. Front Physiol (2018) 9:114:114. doi: 10.3389/fphys.2018.00114

39. Saler T, Cakmak G, Saglam ZA, Ataoglu E, Yesim Erdem T, Yenigun M. The assessment of pulmonary diffusing capacity in diabetes mellitus with regard to microalbuminuria. Intern Med (2009) 48(22):1939-43. doi: 10.2169/ internalmedicine.48.2417

40. Eapen MS, Lu W, Gaikwad AV, Bhattarai P, Chia C, Hardikar A, et al. Endothelial to mesenchymal transition: a precursor to post-COVID-19 interstitial pulmonary fibrosis and vascular obliteration? Eur Respir J (2020) 56:2003167. doi: 10.1183/13993003.03167-2020

41. Gaikwad AV, Eapen MS, Mc Alinden KD, Chia C, Larby J, Myers S, et al. Endothelial to mesenchymal transition (EndMT) and vascular remodeling in pulmonary hypertension and idiopathic pulmonary fibrosis. Expert Rev Respir Med (2020) 14(10):1027-43. doi: 10.1080/17476348.2020.1795832

42. Lv Z, Wang Y, Liu YJ, Mao YF, Dong WW, Ding ZN, et al. NLRP3 Inflammasome Activation Contributes to Mechanical Stretch-Induced Endothelial-Mesenchymal Transition and Pulmonary Fibrosis. Crit Care (2018) 46(1):e49-58. doi: 10.1097/CCM.0000000000002799

43. Xu M, Liu PP, Li H. Innate immune signaling and its role in metabolic and cardiovascular diseases. Physiol Rev (2019) 99:893-948. doi: 10.1152/ physrev.00065.2017

44. Larsen C, Faulenbach M, Vaag A, Ehses JA, Donath M, Mandrup-Poulsen T. Sustained effects of interleukin-1 receptor antagonist treatment in type 2 diabetes. Diabetes Care (2009) 32:1663-8. doi: 10.2337/dc09-0533

45. Gentile S, Strollo F, Ceriello A. COVID-19 infection in Italian people with diabetes: lessons learned for our future, an experience to be used. Diabetes Res Clin Pract (2020) 162:108137. doi: 10.1016/j.diabres. 108137.

46. Lambadiari V, Pavlidis G, Kousathana F, Maratou E, Georgiou D, Andreadou I, et al. Effects of Different Antidiabetic Medications on Endothelial Glycocalyx, Myocardial Function and Vascular Function in Type 2 Diabetic Patients: One year follow-up Study. J Clin Med (2019) 8(7):983. doi: 10.3390/jcm8070983

47. Becker BF, Jacob M, Leipert S, Salmon AHJ, Chappell D. Degradation of the endothelial glycocalyx in clinical settings: searching for the sheddases. $\mathrm{Br} \mathrm{J}$ Clin Pharmacol (2015) 80(3):389-402. doi: 10.1111/bcp.12629

48. Boisramé-Helms J, Kremer H, Schini-Kerth V, Meziani F. Endothelial dysfunction in sepsis. Curr Vasc Pharmacol (2013) 11:150-60. doi: 10.2174/ 1570161111311020005

49. Wassmann S, Stumpf M, Strehlow K, Schmid A, Schieffer B, Böhm M, et al. Interleukin- 6 induces oxidative stress and endothelial dysfunction by overexpression of the angiotensin II type 1 receptor. Circ Res (2004) 94:534-41. doi: 10.1161/01.RES.0000115557.25127.8D

50. Szotowski B, Antoniak S, Poller W, Schultheiss HP, Rauch U. Procoagulant soluble tissue factor is released from endothelial cells in response to inflammatory cytokines. Circ Res (2005) 96:1233-9. doi: 10.1161/01.RES.0000171805.24799.fa

51. Giamarellos-Bourboulis EJ, Netea MG, Rovina N, Akinosoglou K, Antoniadou A, Antonakos N, et al. Complex Immune Dysregulation in COVID-19 Patients with Severe Respiratory Failure. Cell Host Microbe (2020) 27(6):992-1000.e3. doi: 10.1016/j.chom.2020.04.009 
52. Ikonomidis I, Pavlidis G, Katsimbri P, Lambadiari V, Parissis J, Andreadou I, et al. Tocilizumab improves oxidative stress and endothelial glycocalyx: A mechanism that may explain the effects of biological treatment on COVID-19. Food Chem Toxicol (2020) 145:111694. doi: 10.1016/j.fct.2020.111694

53. Ikonomidis I, Pavlidis G, Katsimbri P, Andreadou I, Triantafyllidi H, Tsoumani M, et al. Differential effects of inhibition of interleukin 1 and 6 on myocardial, coronary and vascular function. Clin Res Cardiol (2019) 108:1093-101. doi: 10.1007/s00392-019-01443-9

54. Ceribelli A, Motta F, De Santis M, Ansari AA, Ridgway WM, Gershwin ME, et al. Recommendations for coronavirus infection in rheumatic diseases treated with biologic therapy. J Autoimmun (2020) 109:102442. doi: 10.1016/j.jaut.2020.102442

55. Hulme KD, Gallo LA, Short KR. Influenza virus and glycemic variability in diabetes: a killer combination? Front Microbiol (2017) 8:86. doi: 10.3389/ fmicb.2017.00861

56. Short KR, Kroeze E, Fouchier RAM, Kuiken T. Pathogenesis of influenzainduced acute respiratory distress syndrome. Lancet Infect Diseases (2014) 14 (1):57-69. doi: 10.1016/S1473-3099(13)70286-X

57. Varga Z, Flammer AJ, Steiger P, Haberecker M, Andermatt R, Zinkernagel AS. Endothelial cell infection and endotheliitis in COVID-19. Lancet (2010) 395 (10234):1417-8. doi: 10.1016/S0140-6736(20)30937-5

58. Chritchley JA, Carey IM, Harris T, DeWilde S, Hosking FJ, Cook DG. Glycemic control and risk of infections among people with type 1 or type 2 diabetes in a large primary care cohort study. Diabetes Care (2018) 41 (10):2127-35. doi: 10.2337/dc18-0287

59. Mor A, Dekkers OM, Nielsen JS, Beck-Nielsen H, Sorensen HT, Thomsen RW. Impact of glycemic control on risk of infections in patients with type 2 diabetes: a population-based cohort study. Am J Epidemiol (2017) 186(2):22736. doi: 10.1093/aje/kwx049

60. Allard R, Leclerc P, Tremblay C, Tannenbaum TN. Diabetes and the severity of pandemic influenza A (H1N1) infection. Diabetes Care (2010) 33(7):14913. doi: $10.2337 / \mathrm{dc} 09-2215$

61. Jain S, Kamimoto L, Bramley AM, Schimtz AM, Benoit SR, Louie J, et al. Hospitalized patients with 2009 H1Nlinfluenza in the United States, 2009. New Engl J Med (2009) 36(20):1935-44. doi: 10.1056/NEJMoa0906695

62. Wang W, Chen H, Li Q, Qiu B, Wang J, Sun X, et al. Fasting plasma glucose is an independent predictor for severity of H1N1 pneumonia. BMC Infect Dis (2011) 11:104. doi: 10.1186/1471-2334-11-104

63. Tay MZ, Poh CM, Renia L, MacAry PA, Ng LPF. The trinity of COVID-19: Immunity, inflammation and intervention. Nat Rev Immunol (2020) 20 (6):363-74. doi: 10.1038/s41577-020-0311-8

Conflict of Interest: The authors declare that the research was conducted in the absence of any commercial or financial relationships that could be construed as a potential conflict of interest.

Copyright (c) 2020 Lambadiari, Kousathana, Raptis, Katogiannis, Kokkinos and Ikonomidis. This is an open-access article distributed under the terms of the Creative Commons Attribution License (CC BY). The use, distribution or reproduction in other forums is permitted, provided the original author(s) and the copyright owner(s) are credited and that the original publication in this journal is cited, in accordance with accepted academic practice. No use, distribution or reproduction is permitted which does not comply with these terms. 